\title{
Desempenho produtivo e parâmetros sanguíneos de vacas leiteiras em pastejo suplementadas com resíduos de feijão
}

\author{
Angela Aparecida da Fonseca ${ }^{(1)}$, Anderson de Moura Zanine ${ }^{(2)}$, Marinaldo Divino Ribeiro(3), \\ Fernando de Paula Leonel(4), Daniele de Jesus Ferreira ${ }^{(2)}$, Alexandre Lima de Souza ${ }^{(1)}$, \\ Felipe Gomes da Silva(1), Rafael Arruda Correa(1) e Calixto Ramos Corrêa Neto ${ }^{(1)}$
}

\begin{abstract}
(1)Universidade Federal de Mato Grosso, Avenida Fernando Corrêa da Costa, o 2.367, Bairro Boa Esperança, CEP 78060-900 Cuiabá, MT, Brasil. E-mail: angelaapfonseca@hotmail.com, alexandre@ufmt.br, felipe.melhoramento@hotmail.com, rafael.mt@live.com, calixtotmb@gmail.com (2)Universidade Federal do Maranhão, Departamento de Zootecnia, Rodovia BR 222, Km 4, s/no, CEP 65500-000 Chapadinha, MA, Brasil. E-mail: anderson.zanine@ibest.com.br, dany dosanjos@yahoo.com.br (3)Universidade Federal de Goiás, Departamento de Zootecnia, Avenida Esperança, s/no, CEP 74690-900 Goiânia, GO, Brasil. E-mail: malldorr@gmail.com (4)Universidade Federal de São João Del-Rei, Departamento de Zootecnia, Avenida Visconde do Rio Preto, s/no, CEP $36301-360$ São João del-Rei, MG, Brasil. E-mail: fernandoleonel@ufsj.edu.br
\end{abstract}

Resumo - O objetivo deste trabalho foi avaliar o efeito da alimentação suplementar de resíduos de feijão no desempenho produtivo e nos parâmetros sanguíneos de vacas leiteiras em pastejo. Foram utilizadas oito vacas mestiças, com peso médio de $500 \mathrm{~kg}$, distribuídas em duplo quadrado latino $4 \times 4$, alimentadas com alimentação suplementar de 134, 240, 348 e $449 \mathrm{~g} \mathrm{~kg}^{-1}$ de resíduos de feijão na ração concentrada. Os animais receberam a suplementação após a ordenha no período da manhã e da tarde. A inclusão de resíduos de feijão não alterou os pesos corporais médios e os escores corporais; no entanto, reduziu a produção de leite. Os teores de gordura, proteína bruta, lactose e extrato seco total não foram alterados pela inclusão dos resíduos de feijão. A concentração sanguínea de glicose e colesterol não foi alterada pela adição do resíduo antes do fornecimento de ração concentrada e nem quatro e seis horas após essa alimentação. A inclusão dos resíduos de feijão na ração concentrada de vacas leiteiras em pastejo, com produção média diária de $13 \mathrm{~kg}$, reduz a produção de leite. Todavia, a utilização desses resíduos pouco influencia a composição do leite e os parâmetros sanguíneos.

Termos para indexação: Phaseolus vulgaris, produção de leite, qualidade do leite, subproduto.

\section{Growth performance and blood parameters of dairy cows subjected to grazing and to a supplementary diet of bean residues}

\begin{abstract}
The objective of this work was to evaluate the effect of dietary supplement bean residue on growth performance and blood parameters of dairy cows grazing. Eight crossbred cows weighing $500 \mathrm{~kg}$ were analyzed, distributed in $4 \times 4$ double Latin square, and fed with $134,240,348$, and $449 \mathrm{~g} \mathrm{~kg}^{-1}$ of a supplementary diet of bean waste in the concentrated feed. The animals received the supplementation after milking in the morning and in the afternoon. The inclusion of bean residues did not change average body weights and body scores; however, it reduced the milk production. Fat, protein, lactose, and total solid contents $\left(\mathrm{g} \mathrm{kg}^{-1}\right)$ were not changed by bean waste inclusion. Blood glycose and cholesterol did not change before the offering of the concentrated feed diet, nor after four to six hours of feeding this diet. The inclusion of bean residues in the concentrated feed of dairy cows subjected to grazing, with a daily average production of $13 \mathrm{~kg}$, reduces milk production. However, the use of these residues has little effect on milk composition and blood parameters.
\end{abstract}

Index terms: Phaseolus vulgaris, milk production, milk quality, byproduct.

\section{Introdução}

Para que o produtor brasileiro seja competitivo, é necessário investir em tecnologias nutricionais que permitam que a bovinocultura leiteira produza leite com alto padrão de qualidade e a custo reduzido.

A utilização de subprodutos agroindustriais é uma alternativa para viabilizar um plano nutricional que melhore os índices produtivos de bovinos leiteiros e contribua para a redução dos custos com alimentação; tais resultados são comprovados por diversos autores (Mendes Neto et al., 2007; Maciel et al., 2012).

As despesas com alimentação, normalmente, situam-se entre 50 e $60 \%$ do custo total de produção de leite, e as fontes proteicas são as mais onerosas. Entretanto, sua limitação ou excesso pode afetar a produção e a saúde do rebanho (Paiva et al., 2013). 
Pimentel et al. (2013) ressaltaram a necessidade de pesquisas referentes à utilização de alimentos alternativos que podem viabilizar a atividade pecuária. Por isso, os resíduos oriundos do beneficiamento ou processamento de feijão representam uma alternativa promissora para a suplementação da dieta animal (Goes et al., 2013).

Estudos a respeito de resíduos do beneficiamento de feijão (Phaseolus vulgaris L.) são de grande importância por sua alta disponibilidade regional (Acompanhamento..., 2013). Entretanto, para que se possa incorporar esses resíduos em dietas para ruminantes, são necessários: sua caracterização; o conhecimento prévio da sua composição bromatológica; a aceitabilidade pelos animais; a produção e composição do leite; e a eficiência alimentar (Magalhães et al., 2008).

Os resíduos de feijão, em sua composição, apresentam, em média: $89 \%$ de matéria seca (MS); $23 \%$, proteína bruta $(\mathrm{PB}) ; 1,67 \%$, extrato etéreo (EE); $21 \%$, fibra em detergente neutro (FDN); $\%$, fibra em detergente ácido (FDA); 7,81\%, proteína insolúvel em detergente neutro (PIDN); 1,51\%, proteína insolúvel em detergente ácido (PIDA); 5,11\%, matéria mineral (MM); e 1,4\% de lignina (Magalhães et al., 2008).

Apesar do potencial, são escassas as pesquisas com resíduos de feijão como fonte de suplementação de bovinos leiteiros em pastejo, a maioria dos trabalhos com esse resíduo é relatada em condições de confinamento (Magalhães et al., 2008; Goes et al., 2013). Há carência de informações a respeito do nível adequado de resíduos de feijão relacionado ao consumo, ao ganho de peso, à produção e qualidade do leite e aos parâmetros sanguíneos, por meio das respostas produtivas de vacas em lactação criadas em pasto.

Por conseguinte, é importante entender que a alimentação e o estado fisiológico dos animais (puberdade, gestação, lactação) impõem condições metabólicas que determinam o desempenho produtivo deles. Assim, a inclusão das análises dos parâmetros sanguíneos, além dos produtivos, permite avaliar, diagnosticar e prevenir transtornos metabólicos, por meio do estudo da adaptação do animais diante dos desafios nutricionais e fisiológicos impostos pela inclusão ou substituição de novos ingredientes em dietas (Freitas Júnior et al., 2010).

O objetivo deste trabalho foi avaliar o efeito da alimentação suplementar de resíduos de feijão no desempenho produtivo e nos parâmetros sanguíneos de vacas leiteiras em pastejo.

\section{Material e Métodos}

O experimento foi realizado de maio a julho de 2012, na Fazenda Experimental Risoleta Neves, a $21^{\circ} 06^{\prime} \mathrm{S}$, $44^{\circ} 15^{\prime} \mathrm{W}$, à altitude de $889 \mathrm{~m}$, no município de São João del Rei, MG. O clima, segundo a classificação de Köppen-Geiger, é do tipo Cwb - subtropical moderado úmido ou tropical de altitude -, com duas estações bem definidas (verão quente e úmido e inverno frio e seco). A temperatura média anual foi de $18.5^{\circ} \mathrm{C}$, tendo oscilado entre 15 e $22^{\circ} \mathrm{C}$, para as médias de mínima e máxima, respectivamente. A umidade relativa do ar teve média de $80 \%$, e a precipitação média anual foi em torno de $1.500 \mathrm{~mm}$.

Utilizaram-se oito vacas mestiças (Holandês $\mathrm{x}$ Zebu), em fase de lactação entre 60 e 90 dias, com peso médio de $500 \mathrm{~kg}$ e produção média de $13 \mathrm{~kg}$ de leite por dia. Os animais foram distribuídos em um duplo quadrado latino de $4 \times 4$ (4 tratamentos x 4 períodos), para testar quatro níveis $\left(134,240,348\right.$ e $\left.449 \mathrm{~g} \mathrm{~kg}^{-1}\right)$ de inclusão dos resíduos de feijão na suplementação concentrada (Tabela 1), com relação 80:20 de volumoso:concentrado.

O período experimental teve duração de 84 dias, subdivididos em quatro subperíodos de 21 dias cada um. Os primeiros 15 dias de cada subperíodo foram utilizados para adaptação dos animais aos tratamentos, e os seis dias restantes, para as coletas.

Os animais foram manejados pelo método de pastejo com lotação rotativa e foram mantidos em piquetes de 0,5 ha. Durante o período experimental, os animais foram alocados em quatro piquetes de Urochloa brizantha 'Xaraés' (Syn. Brachiaria brizantha 'Xaraés') e quatro piquetes de Panicum maximum 'Mombaça', providos de bebedouros e saleiros. A altura de pré e pós pastejo foram respectivamente de: 35 e $20 \mathrm{~cm}$, para o capim-xaraés; e de 80 e $35 \mathrm{~cm}$, para o capim-mombaça. Após a saída dos animais de cada piquete, realizou-se a adubação com $50 \mathrm{~kg}$ da fórmula $\mathrm{N}-\mathrm{P}_{2} \mathrm{O}_{5}-\mathrm{K}_{2} \mathrm{O}$ 20-05-20 para a manutenção do pasto.

Os suplementos experimentais foram formulados para serem isonitrogenados, conforme National Research Council (2001). Nos dois últimos períodos do experimento, os animais receberam suplementação com volumoso à base de cana-de-açúcar com ureia e sulfato de amônio, à proporção de 6:1. Os animais receberam essa 
suplementação à base de cana-de-açúcar em decorrência do período de transição da estação das águas para a seca, em que a forragem do pasto não foi suficiente para atender a exigência nutricional dos animais; no presente estudo, não foi possível utilizar carga animal variável, pois não havia piquetes que poderiam receber o excesso de animais naquele dado momento.

No entanto, a estrutura dos pastos de capim-xaraés foi semelhante à das recomendações de manejo de pastejo por Pedreira \& Pedreira (2007) e à das recomendadas para capim-mombaça preconizadas por Euclides et al. (2015).

As amostras de matéria seca (MS) total de forragem foram obtidas por meio da técnica de amostragem do quadrado no pré-pastejo, ou seja, foram coletadas com corte rente ao solo, de quatro áreas por piquete, com um quadrado metálico de $1 \times 1 \mathrm{~m}$. Os valores de massa de MS total de forragem correspondente ao primeiro, segundo, terceiro e quarto períodos experimentais foram $8.153,15,8.333,79,4.082,86$ e $3.157,90 \mathrm{~kg}$ de $\mathrm{MS} \mathrm{ha}^{-1}$, respectivamente.

As amostras dos suplementos e dos ingredientes foram obtidas por ocasião da mistura dos ingredientes. As amostras das sobras foram coletadas antes de se realizar o fornecimento do suplemento aos animais pela manhã e tarde.

Tabela 1. Proporção dos ingredientes da dieta e composição química dos resíduos de feijão e de milho.

\begin{tabular}{|c|c|c|c|c|}
\hline \multirow{2}{*}{$\begin{array}{l}\text { Ingrediente } \\
\text { Resíduos de Feijão }\end{array}$} & \multicolumn{4}{|c|}{$\begin{array}{l}\text { Proporção dos ingredientes na dieta } \\
\qquad\left(\mathrm{g} \mathrm{kg}^{-1} \mathrm{MS}\right)\end{array}$} \\
\hline & 134 & 240 & 348 & 449 \\
\hline Milho moído & 808 & 707 & 603 & 508 \\
\hline Calcário calcítico & 15 & 15 & 15 & 15 \\
\hline Fosfato bicálcico & 8 & 8 & 8 & 8 \\
\hline Ureia protegida & 35 & 30 & 25 & 20 \\
\hline Total & 1.000 & 1.000 & 1.000 & 1.000 \\
\hline Composição & \multicolumn{2}{|c|}{ Resíduos de feijão } & \multicolumn{2}{|c|}{ Milho moído } \\
\hline Matéria seca & \multicolumn{2}{|c|}{939,40} & \multicolumn{2}{|c|}{909,10} \\
\hline Matéria orgânica & \multicolumn{2}{|c|}{953,30} & \multicolumn{2}{|c|}{984,30} \\
\hline Matéria mineral & \multicolumn{2}{|c|}{46,70} & \multicolumn{2}{|c|}{15,70} \\
\hline Proteína bruta & \multicolumn{2}{|c|}{205,40} & \multicolumn{2}{|c|}{81,00} \\
\hline Fibra em detergente neutro & \multicolumn{2}{|c|}{184} & \multicolumn{2}{|c|}{115,60} \\
\hline $\mathrm{FDNcp}^{(1)}$ & \multicolumn{2}{|c|}{158,90} & \multicolumn{2}{|c|}{108,10} \\
\hline $\mathrm{FDNi}^{(2)}$ & \multicolumn{2}{|c|}{25,70} & \multicolumn{2}{|c|}{63,10} \\
\hline Extrato etéreo & \multicolumn{2}{|c|}{13,20} & \multicolumn{2}{|c|}{56,90} \\
\hline Carboidratos totais & \multicolumn{2}{|c|}{784,70} & \multicolumn{2}{|c|}{839,80} \\
\hline Carboidratos não fibrosos & \multicolumn{2}{|c|}{575,90} & \multicolumn{2}{|c|}{731,70} \\
\hline
\end{tabular}

Ao final do experimento, foram formadas amostras compostas por animal e período, para se proceder às análises correspondentes. O material foi pré-seco em estufa de ventilação forçada de ar, a $60 \pm 1^{\circ} \mathrm{C}$ por aproximadamente 72 horas e, em seguida, foi moído em moinho tipo Willey, com peneiras de malha de $1 \mathrm{~mm}$.

Após serem moídas, as amostras foram armazenadas em potes de plástico, para análises posteriores dos teores de matéria seca (MS), matéria orgânica (MO), proteína bruta $(\mathrm{PB})$, extrato etéreo $(\mathrm{EE})$, matéria mineral (MM), fibra em detergente neutro (FDN), fibra em detergente neutro indigestível (FDNi) e proteína insolúvel em detergente neutro (PIDN) (Tabela 2), conforme metodologias descritas por Detmann et al. (2012). Os resíduos da fibra em detergente neutro foram corrigidos para cinzas e proteínas.

As vacas foram ordenhadas duas vezes ao dia, às 6:00 e às 16:00 h, com auxílio de uma ordenhadeira mecânica. Após a ordenha, as vacas receberam suplemento concentrado, com 134, 240, 348 e 449\% de resíduos de feijão, com base na matéria seca (Tabela 1). A suplementação foi de $60 \%$ no período da manhã e $40 \%$ no período da tarde.

A produção de leite foi registrada pelo dispositivo acoplado ao sistema de ordenha, entre o $16^{\circ}$ e $21^{\circ}$ dia de cada período experimental. A produção de leite corrigida (PLC) para 3,5\% de gordura foi estimada conforme Sklan et al. (1992). Entre o $20^{\circ}$ e o $21^{\circ}$ dia de cada período experimental, realizaram-se as coletas de amostras de leite provenientes das ordenhas da manhã e da tarde, constituídas de forma proporcional à produção de cada ordenha, no total de aproximadamente $100 \mathrm{~mL}$ cada. As amostras foram embaladas em frascos de plástico com o conservante bronopol (The Boots Company PLC, Nottingham, Inglaterra) e refrigeradas para posteriores análises da composição e qualidade do leite.

Ao final do período experimental, as amostras de leite foram compostas por animal, tratamento e período. Nelas, foram avaliados os teores de sólidos totais, proteína bruta, gordura e lactose, por meio de analisador infravermelho. A contagem de células somáticas foi executada por contador eletrônico Somacount 500 (Bentley Instruments, Chaska, MN, EUA).

O consumo de matéria seca total foi obtido pela soma do consumo de MS do suplemento, estimativa do 
consumo de MS de forragem e estimativa do consumo de MS da cana-de-açúcar. O consumo dos suplementos foi determinado durante o $11^{\circ}$ e o $15^{\circ}$ dias de cada período, tendo-se subtraído as sobras do cocho do suplemento oferecido, que foram coletadas e pesadas duas vezes ao dia.

A estimativa da excreção fecal por animal e período experimental foi obtida por meio da utilização de marcador externo óxido cromo $\left(\mathrm{Cr}_{2} \mathrm{O}_{3}\right)$, fornecido aos animais por via oral em doses diárias de $15 \mathrm{~g}$. No 11을 $13^{\circ}$ e $14^{\circ}$ dia de cada período experimental, foram colhidas amostras diretamente do reto dos animais, para determinação da concentração de óxido cromo das fezes. As amostras coletadas logo após o consumo de suplemento da manhã e da tarde foram acondicionadas em sacos de plástico identificados e congeladas a $-10^{\circ} \mathrm{C}$.

A excreção da matéria seca fecal foi calculada com base na razão entre a quantidade do indicador fornecido e sua concentração nas fezes. Em seguida, estimou-se o consumo de matéria seca da forragem (CMSF) e do concentrado (CMSC), tendo-se utilizado a fibra em detergente neutro indigestível (FDNi) como indicador interno.

$\mathrm{Na}$ ocasião das pesagens dos animais, realizaramse também as avaliações de condição corporal, por uma única pessoa treinada, segundo a metodologia proposta por Ferreira \& Torres (1993). As avaliações foram realizadas ao início e ao final de cada período experimental, após a segunda ordenha.

Coletaram-se amostras de sangue no $21^{\circ}$ dia de cada período, através de punção da veia jugular, em tubo a vácuo que permaneceu inclinado, à temperatura ambiente, até o sangue coagular e retrair o coágulo, com o soro exsudado após 30 a $60 \mathrm{~min}$. O soro plasmático foi transferido para tubos de Eppendorf e armazenado a $-10^{\circ} \mathrm{C}$ para posteriores análises de ureia, glicose, colesterol e triglicerídeos, por meio de kits comerciais (Labtest Diagnóstica S.A., Belo Horizonte, MG), segundo orientações dos fabricantes, e a leitura foi realizada em analisador automático de bioquímica sanguínea. A primeira coleta de sangue foi realizada antes da alimentação, e as demais, a cada duas horas $(2,4$, e 6 horas) a partir da alimentação, no total de quatro amostragens. Parte do sangue coletado foi utilizada para avaliar a função hepática, por meio da enzima gama glutamiltransferase sérica, e a função renal, por meio da creatinina cinase sérica.

Dois modelos estatísticos foram utilizados: o primeiro continha os efeitos linear e quadrático dos níveis de inclusão e os efeitos de quadrado latino, animal dentro de quadrado latino e período, conforme a equação $Y_{\mathrm{ijkl}}=\mu+\beta_{1} \cdot \mathrm{x}_{\mathrm{i}}+\beta_{2} \cdot \mathrm{x}^{2}{ }_{\mathrm{i}}+\mathrm{q}_{\mathrm{j}}+\mathrm{a}_{\mathrm{k}(\mathrm{j})}+\mathrm{p}_{\mathrm{l}}+$ $\varepsilon_{\mathrm{ijk} k}$, em que: $\mathrm{Y}_{\mathrm{ijkl}}$ é a observação referente ao i-ésimo tratamento, j-ésimo quadrado latino, k-ésimo animal dentro de quadrado latino $\mathrm{j}$, e l-ésimo período; $\mu$ é a média geral; $\beta_{1}$ e $\beta_{2}$ são os coeficientes de regressão dos efeitos do tratamento i, em que $i=1,2,3$ e 4 , com efeitos linear e quadrático, respectivamente; Qj é o efeito do quadrado latino $\mathrm{j}, \mathrm{com} \mathrm{j}=1$ e $2 ; \mathrm{a}_{\mathrm{k}}$ é o efeito do animal $\mathrm{k}$ dentro de quadrado latino, $\mathrm{k}=1,2,3 \mathrm{e}$ 4; $\mathrm{p}_{1}$ é o efeito do período $1,1=1,2,3$ e $4 ; \varepsilon_{\mathrm{ijkl}}$ é o erro aleatório associado a cada observação. O segundo modelo foi semelhante ao primeiro, tendo-se removido

Tabela 2. Composição química dos suplementos experimentais e do pasto, de acordo com os níveis de inclusão dos resíduos de feijão e dos períodos de pastejo da forragem $\left(\mathrm{g} \mathrm{kg}^{-1} \mathrm{MS}\right)$.

\begin{tabular}{|c|c|c|c|c|c|c|c|c|c|}
\hline \multirow[t]{2}{*}{ Ingrediente } & \multicolumn{4}{|c|}{ Níveis de resíduos de feijão $\left(\mathrm{g} \mathrm{kg}^{-1}\right)$} & \multicolumn{4}{|c|}{ Períodos de pastejo da forragem } & \multirow[t]{2}{*}{ Cana } \\
\hline & 134 & 240 & 348 & 449 & 1 & 2 & 3 & 4 & \\
\hline Matéria seca & 900,80 & 899,60 & 904,20 & 906,50 & 190,40 & 192,10 & 203,70 & 208,20 & 304,30 \\
\hline Matéria orgânica & 950,10 & 951,40 & 940,20 & 939,50 & 884,30 & 899,50 & 878,00 & 898,60 & 964,50 \\
\hline Matéria mineral & 49,90 & 48,60 & 59,80 & 60,50 & 115,70 & 100,50 & 122,00 & 101,40 & 35,50 \\
\hline Proteína bruta & 111,10 & 121,20 & 151,30 & 180,90 & 118,20 & 95,20 & 76,50 & 84,80 & 14,40 \\
\hline Fibra em detergente neutro & 173,30 & 185,70 & 223,70 & 217,00 & 775,20 & 768,00 & 769,00 & 739,20 & 485,70 \\
\hline $\mathrm{FDNcp}^{(1)}$ & 171,50 & 183,50 & 220,30 & 214,10 & 752,10 & 750,50 & 748,50 & 721,80 & 482,30 \\
\hline $\mathrm{FDNi}^{(2)}$ & 30,50 & 15,60 & 16,70 & 14,30 & 220,50 & 233,70 & 273,90 & 231,70 & 230,20 \\
\hline Extrato etéreo & 3,06 & 2,11 & 2,13 & 0,47 & 13,10 & 20,20 & 9,40 & 8,70 & 11,20 \\
\hline Carboidrato total & 806,9 & 807,6 & 766,2 & 751,6 & 756,50 & 782,50 & 790,50 & 804,00 & 936,30 \\
\hline Carboidrato não fibroso & 635,4 & 624,1 & 545,8 & 537,5 & 4,50 & 29,00 & 42,00 & 82,3 & 454,00 \\
\hline
\end{tabular}

${ }^{(1)}$ Fibra em detergente neutro corrigido para cinza e proteína. ${ }^{(2)}$ Fibra em detergente neutro indigestível. 
apenas o efeito quadrático do nível de inclusão, para testar adequadamente o efeito linear de primeiro grau do nível de inclusão.

Os dados foram submetidos à análise de regressão, e a escolha dos modelos baseou-se na significância dos parâmetros de regressão, a 5\% de probabilidade, pelo PROC GLM do SAS (SAS Institute, Cary, NC, EUA).

\section{Resultados e Discussão}

Os pesos corporais (PC) médios e os escores corporais não foram alterados $(\mathrm{p}>0,05)$ pela inclusão de 134, 240, 348 e $449 \mathrm{~g} \mathrm{~kg}^{-1}$ de resíduos de feijão na ração concentrada, tendo-se observado valores médios de $525,7,523,0,523,9$ e $524,2 \mathrm{~kg}$ por vaca, e 3,2 , $3,0,3,1$ e 3,2 de escores corporais, respectivamente. Todavia, os valores da produção de leite e da produção de leite corrigida para $3,5 \%$ de gordura foram alterados $(\mathrm{p}<0,05)$ pelos resíduos de feijão (Tabela 3 ), com estimativas de redução de 43,4 e 36,2 g por dia, para cada unidade percentual de resíduo adicionado à ração concentrada.

A redução da produção de leite e da produção de leite corrigido para gordura pode ser atribuída, principalmente, ao efeito negativo dos resíduos de feijão sobre os consumos $(p<0,05)$ de pasto, suplementação volumosa e das dietas utilizados nesta pesquisa (Tabela 3), bem como à presença de maior quantidade de FDN e menor teor de CNF nos resíduos de feijão, em comparação ao milho (Tabela 1). A redução da produção de leite e da produção de leite corrigido para gordura também pode ter ocorrido em razão da presença de compostos antinutricionais no feijão, principalmente taninos, que reduzem a digestibilidade das proteínas e dos carboidratos em relação aos demais cerais (Bonett et al., 2007). Ao utilizarem vacas da raça Holandesa, no terço inicial da lactação, com média de produção de $22 \mathrm{~kg}$ por dia, Magalhães et al. (2008)

Tabela 3. Valores médios da produção de leite, produção de leite corrigida para 3\% de gordura (PLCg), gordura, proteína bruta, lactose, estrato seco total (EST) e estrato seco desengordurado (ESD), contagem de células somáticas (CCS), teor de N ureico no leite (NUL), análise de caseína (CAS) e percentual de proteínas na caseína (PCAS) de vacas mestiças, suplementadas com níveis de resíduos de feijão.

\begin{tabular}{|c|c|c|c|c|c|c|c|}
\hline \multirow[t]{2}{*}{ Item } & \multicolumn{4}{|c|}{ Níveis de inclusão de resíduos de feijão $\left(\mathrm{g} \mathrm{kg}^{-1}\right)$} & \multirow{2}{*}{$\begin{array}{l}\text { CV } \\
(\%)\end{array}$} & \multicolumn{2}{|c|}{ Valor $\mathrm{p}$} \\
\hline & 134 & 240 & 348 & 449 & & $\mathrm{~L}^{(1)}$ & $\mathrm{Q}^{(1)}$ \\
\hline Produção de leite ${ }^{(2)}$ (kg por dia) & 11,41 & 10,83 & 10,27 & 10,07 & 6,91 & 0,0007 & 0,4917 \\
\hline PLCg $3,5 \%{ }^{(3)}(\mathrm{kg}$ por dia $)$ & 10,37 & 10,14 & 9,77 & 9,26 & 9,20 & 0,0142 & 0,7712 \\
\hline Gordura $^{(4)}$ (kg por dia) & 0,37 & 0,34 & 0,32 & 0,30 & 12,96 & 0,0024 & 0,6230 \\
\hline Proteína bruta ${ }^{(5)}(\mathrm{kg}$ por dia $)$ & 0,36 & 0,35 & 0,32 & 0,31 & 10,95 & 0,0110 & 0,4726 \\
\hline Lactose $^{(6)}$ (kg por dia) & 0,54 & 0,52 & 0,47 & 0,48 & 6,66 & 0,0005 & 0,5279 \\
\hline $\mathrm{EST}^{(7)}(\mathrm{kg}$ por dia $)$ & 1,38 & 1,31 & 1,20 & 1,20 & 7,27 & 0,0004 & 0,4596 \\
\hline $\operatorname{ESD}^{(8)}(\mathrm{kg}$ por dia $)$ & 1,00 & 0,97 & 0,87 & 0,88 & 7,32 & 0,0005 & 0,7253 \\
\hline Gordura $\left(\mathrm{g} \mathrm{kg}^{-1}\right)$ & 33,5 & 32,1 & 33,3 & 30,8 & 12,80 & 0,2368 & 0,9980 \\
\hline Proteína bruta $\left(\mathrm{g} \mathrm{kg}^{-1}\right)$ & 31,7 & 32,5 & 33,3 & 30,8 & 10,72 & 0,7726 & 0,1559 \\
\hline Lactose $\left(\mathrm{g} \mathrm{kg}^{-1}\right)$ & 46,9 & 47,4 & 46,6 & 46,8 & 1,59 & 0,6076 & 0,1673 \\
\hline $\operatorname{EST}\left(\mathrm{g} \mathrm{kg}^{-1}\right)$ & 121,2 & 121,3 & 121,0 & 119,9 & 3,57 & 0,4482 & 0,8923 \\
\hline $\operatorname{ESD}\left(\mathrm{g} \mathrm{kg}^{-1}\right)$ & 87,7 & 89,2 & 87,7 & 86,8 & 2,25 & 0,2390 & 0,0841 \\
\hline CCS (mil células $\mathrm{mL}^{-1}$ ) & 150,25 & 92,75 & 134,14 & 123,12 & 85,41 & 0,7189 & 0,3702 \\
\hline NUL (mg dL $\left.{ }^{-1}\right)$ & 14,36 & 12,14 & 13,73 & 15,02 & 23,87 & 0,6337 & 0,0735 \\
\hline CAS $(\% \mathrm{~m} / \mathrm{m})$ & 2,30 & 2,41 & 2,34 & 2,26 & 6,40 & 0,4467 & 0,0931 \\
\hline PCAS (\% PROT) & 74,99 & 75,82 & 75,46 & 75,39 & 2,09 & 0,6541 & 0,2948 \\
\hline \multicolumn{8}{|c|}{ Consumo de matéria seca ( $\mathrm{kg}$ por dia) } \\
\hline Concentrado & 4,23 & 3,67 & 2,99 & 3,26 & 37,63 & 0,8208 & 0,0501 \\
\hline Pasto $^{(9)}$ & 13,01 & 13,65 & 8,78 & 8,84 & 17,23 & 0,0030 & 0,0855 \\
\hline Cana $^{(10)}$ & 2,56 & 0,81 & 0,52 & 0,62 & 22,38 & 0,0003 & 0,1863 \\
\hline Dieta $^{(11)}$ & 18,99 & 18,13 & 12,35 & 12,74 & 16,75 & $<, 0001$ & 0,5434 \\
\hline
\end{tabular}

${ }^{(1)}$ Efeitos de ordem linear (L) e quadrática (Q), relativos à inclusão de resíduos de feijão no suplemento, a 5\% de probabilidade. ${ }^{(2)} \hat{Y}=11,9172-0,00434 \mathrm{x}$ $\left(\mathrm{R}^{2}=0,87\right) ;{ }^{(3)} \hat{\mathrm{Y}}=10,9187-0,00362 \mathrm{x}\left(\mathrm{R}^{2}=0,71\right) ;{ }^{(4)} \hat{\mathrm{Y}}=0,4006-0,00023 \mathrm{x}\left(\mathrm{R}^{2}=0,75\right) ;{ }^{(5)} \hat{\mathrm{Y}}=0,3820-0,00016 \mathrm{x}\left(\mathrm{R}^{2}=0,60\right) ;{ }^{(6)} \hat{\mathrm{Y}}=0,5626-0,00021 \mathrm{x}$ $\left(\mathrm{R}^{2}=0,91\right) ;{ }^{(7)} \hat{\mathrm{Y}}=1,4508-0,00061 \mathrm{x}\left(\mathrm{R}^{2}=0,80\right) ;{ }^{(8)} \hat{\mathrm{Y}}=1,0579-0,00043 \mathrm{x}\left(\mathrm{R}^{2}=0,86\right) ;{ }^{(9)} \hat{\mathrm{Y}}=15,9227-0,01658 \mathrm{x}\left(\mathrm{R}^{2}=0,66\right) ;{ }^{(10)} \hat{\mathrm{Y}}=3,2152-0,00714 \mathrm{x}$ $\left(\mathrm{R}^{2}=0,98\right) ;{ }^{(11)} \hat{\mathrm{Y}}=22,4015-0,02340 \mathrm{x}\left(\mathrm{R}^{2}=0,74\right)$. 
estimaram reduções de $30,8 \mathrm{~g}$ por dia da produção de leite, para cada unidade de resíduo de feijão, em substituição ao farelo de soja da ração concentrada.

Os componentes do leite foram alterados $(p>0,05)$ em consequência da adição de resíduos de feijão à ração concentrada. Para os teores de gordura, proteína, lactose, extrato seco total e extrato seco desengordurado, foram estimadas reduções de 2,3, 1,6, 2,1, 6,1 e 4,3 g por dia, para cada unidade percentual de resíduos de feijão adicionada à ração concentrada, respectivamente. A redução dos componentes do leite observada nesta pesquisa está associada, principalmente, à redução da produção de leite expressa em quilogramas por dia (Tabela 3 ). Observou-se comportamento semelhante aos descritos por Magalhães et al. (2008), que estimaram reduções de $1,2,1,1,2,0,4,6$ e $3,5 \mathrm{~g}$ por dia dos teores de gordura, proteína, lactose, estrato seco total e extrato seco desengordurado, respectivamente, para cada unidade percentual de resíduos de feijão adicionados à ração concentrada, para vacas com potencial de produção de $6.000 \mathrm{~kg}$ por lactação, respectivamente.

A fermentação dos CNF no rúmen contribui para o aumento da produção de ácido propiônico, principal responsável pela síntese de glicose, molécula primer da produção de galactose e lactose, no parênquima da glândula mamária (Paiva et al., 2013). Em razão da grande capacidade de exercer pressão osmótica no lúmen dos alvéolos mamários, a lactose constitui o principal nutriente relacionado à quantidade de leite produzido. Assim, os menores teores de CNF dos resíduos de feijão, em comparação ao milho (Tabela 1), e a redução desta fração nos suplementos experimentais com adição de resíduos de feijão (Tabela 2) explicam parte da redução das quantidades de lactose e de leite, em quilogramas por dia, observados nesta pesquisa.

Destaca-se que os valores médios de gordura $(3,24 \%)$, proteína bruta $(3,20 \%)$ e sólidos desengordurados $(8,78 \%)$, estimados nesta pesquisa, estão acima dos valores mínimos de gordura $(3,0 \%)$, proteína $(2,9 \%)$ e sólidos desengordurados $(8,4 \%)$ recomendados pela Instrução Normativa no 62 (Brasil, 2011). Este fato é de relevância para as indústrias de derivados lácteos, pois elas visam matéria prima de qualidade, com maior concentração de sólidos totais - em torno de 12,5\%.

A lactose destaca-se como um dos componentes mais estáveis do leite, no entanto, já se esperavam alterações na concentração dos componentes do leite, em especial as dos teores de gordura, com a redução do consumo de pasto, de cana-de-açúcar e da dieta, em razão da adição dos resíduos de feijão à ração concentrada (Tabela 3). De acordo com Oliveira et al. (2014), para dietas com maior proporção de volumoso, ocorre aumento do $\mathrm{pH}$ e beneficiamento da atividade das bactérias celulolíticas, o que gera maior produção de ácido acético, precursor da gordura do leite. Todavia, independentemente do nível de resíduos de feijão no concentrado, não foi observada diferença significativa $(p<0,05)$ na concentração dos componentes do leite expresso em gramas por quilograma. A ausência de alterações na concentração dos componentes do leite tem sido relatada mesmo em condições de variações de volumoso, concentrado, resíduos ou subprodutos utilizados e do nível de nível de proteína da dieta (Pimentel et al., 2013; Oliveira et al., 2014)

A caseína do leite é um importante nutriente de interesse para as indústrias, pois é a principal proteína relacionada ao processo de fabricação de queijo. A caseína e seu percentual em relação ao teor de proteína bruta não foram alterados $(\mathrm{p}>0,05)$ pelos níveis de resíduos de feijão na ração concentrada. Possivelmente, as dietas utilizadas proporcionaram valores adequados de aminoácidos ao tecido secretor de leite, pois os valores médios de caseína $(2,33 \%)$ e seu percentual, em relação ao teor de proteína bruta $(75,41 \%)$, estão em de acordo com os resultados descritos na literatura (Duarte et al., 2005).

Os teores de nitrogênio ureico do leite (NUL) não foram alterados $(\mathrm{p}>0,05)$ pela adição de resíduos de feijão à ração concentrada, e tiverem valor médio de 13,81 $\mathrm{mg} \mathrm{dL}^{-1}$ (Tabela 3). Valores médios de $\mathrm{N}$ ureico no leite abaixo de $12 \mathrm{mg} \mathrm{dL}^{-1}$ indicam deficiência proteica ou excesso de carboidratos na dieta, o que pode limitar a fermentação ruminal, a produção de proteína microbiana e o desempenho do animal (Butler, 2000). Valores acima de $18 \mathrm{mg} \mathrm{dL}^{-1}$ representam perdas energéticas para eliminação da ureia, problemas reprodutivos, deficiência imunológica, perdas proteicas e, ainda, contaminação ambiental. Dieta balanceada com volumoso, concentrado e energia permitem que os índices de $\mathrm{N}$ ureico do leite se mantenham adequados (11 a $16 \mathrm{mg} \mathrm{dL}^{-1}$ ) e, consequentemente, aumenta, a produção de leite com qualidade (Rosa et al., 2012).

A contagem de células somáticas (CCS) é relacionada ao percentual de gordura e proteína do leite, de forma que o aumento da CCS tende a reduzir 
os teores destes nutrientes (Bueno et al., 2005). A CCS não foi alterada $(\mathrm{p}>0,05)$ pelos níveis de inclusão de resíduos de feijão. Esta variável é utilizada como uma das principais ferramentas de avaliação da saúde da glândula mamária, além de ser indicativo da qualidade do leite (Rysanek \& Babak, 2005). O valor médio da CCS $\left(125.065 \mathrm{~mL}^{-1}\right)$ verificado nesta pesquisa confirma que as vacas apresentavam úberes sadios. De acordo com a Instrução Normativa no ${ }^{-62}$, como parâmetro de qualidade, o leite deve apresentar valor máximo de CCS de 500 mil células $\mathrm{mL}^{-1}$ (Brasil, 2011).

$\mathrm{O}$ consumo de matéria seca do suplemento não foi alterado $(p>0,05)$ pelos níveis de resíduos de feijão na ração concentrada, tendo-se observado valor médio de $3,54 \mathrm{~kg}$ por dia. A inclusão de 134, 240,348 e $449 \mathrm{~g} \mathrm{~kg}^{-1}$ de resíduos de feijão no concentrado resultou em consumos diários de 1,08, 1,68, 1,99e 2,79 $\mathrm{g} \mathrm{kg}^{-1}$ de peso corporal, respectivamente. Os consumos de matéria seca de pasto, de cana-de-açúcar e da dieta (Tabela 3) foram alterados ( $p<0,05)$, com reduções de 165,8, 71,4 e 234,0 g por dia, respectivamente, para cada unidade percentual de inclusão dos resíduos de feijão na ração concentrada. A redução do consumo de matéria seca da dieta pode ser atribuída à baixa aceitabilidade dos resíduos de feijão, em consequência da presença de taninos e do aumento da pulverulência do concentrado (Magalhães et al., 2008). Para vacas de $500 \mathrm{~kg}$ de peso corporal e produção diária de 10 a $12 \mathrm{~kg}$ de leite corrigido para $3,5 \%$ de gordura, estimam-se consumos de matéria seca de 13,5 a 14,8 $\mathrm{kg}$ por dia (National Research Council, 2001), valores que correspondem às inclusões máximas de 380 a $324 \mathrm{~g} \mathrm{~kg}^{-1}$ de resíduos de feijão na ração concentrada. A concentração sanguínea de glicose, antes da suplementação e quatro e seis horas após a suplementação, não foi alterada $(p>0,05)$ pela adição de resíduos de feijão à ração concentrada (Tabela 4), e apresentou valores médios de 45,28, 53,31, $53,31 \mathrm{mg} \mathrm{dL}^{-1}$, respectivamente. Este comportamento pode ser atribuído a dois fatores principais: aos tempos de coleta e à velocidade de utilização de glicose pelos tecidos do corpo, especialmente em animais em lactação. Todavia, a concentração de glicose duas horas após a alimentação concentrada foi alterada $(p<0,05)$, com estimativa de redução de $0,018 \mathrm{mg}$ $\mathrm{dL}^{-1}$, para cada unidade percentual de inclusão dos resíduos de feijão na ração concentrada. Esta resposta pode ser atribuída aos menores teores de carboidrato não fibrosos presentes nos resíduos de feijão, em comparação ao milho (Tabela 1), e nos suplementos com maiores níveis de inclusão destes resíduos (Tabela 2). Independentemente dos níveis de resíduos de feijão e dos tempos de avaliações, as concentrações de glicose obtidas nesta pesquisa estão na faixa de variação normal de 42 a $74 \mathrm{mg} \mathrm{dL}^{-1}$ (Calixto Junior et al., 2010).

A concentração de colesterol, antes do fornecimento de ração concentrada e quatro e seis horas após o fornecimento, não foi alterada $(\mathrm{p}>0,05)$ pelos níveis de resíduos de feijão, tendo-se registrado valores médios de 170,67, 147,95, 158,06 mg dL ${ }^{-1}$, respectivamente. Entretanto, para o tempo de amostragem de duas horas, verificou-se efeito $(\mathrm{p}<0,05)$ dos níveis de resíduos de feijão sobre os teores de colesterol do sangue, com aumento de $0,16 \mathrm{mg} \mathrm{dL}^{-1}$ para cada unidade percentual de resíduos de feijão adicionados à ração concentrada. A determinação dos níveis plasmáticos de colesterol é um bom indicador do metabolismo energético no fígado, principalmente na exportação de lipídios na forma de lipoproteínas de muito baixa densidade (Ndlovu et al., 2007). Níveis plasmáticos baixos de colesterol indicam um quadro de deficit energético e comprometimento da função hepática (Pimentel et al., 2013), enquanto concentrações aumentadas predispõem à ocorrência de distúrbios metabólicos. Independentemente dos níveis de resíduos de feijão e dos tempos de avaliações, as concentrações de colesterol obtidos nesta pesquisa estão próximos aos valores de 133 a $190 \mathrm{mg} \mathrm{dL}^{-1}$, registrados por Pogliani \& Birgel Junior (2007) e Barletta et al. (2012), respectivamente.

Os teores de triglicerídeos no sangue, antes do fornecimento de ração concentrada e duas e seis horas após o fornecimento, foram alterados $(\mathrm{p}<0,05)$ pelos níveis de resíduos de feijão, com acréscimos de 0,013 , 0,005 e 0,009 , respectivamente. Para o tempo de quatro horas, verificou-se efeito quadrático $(p<0,05)$ dos níveis de resíduos de feijão sobre os teores de triglicerídeos (Tabela 4). Acréscimos às concentrações de triglicerídeos sanguíneos indicam mobilização de reservas corporais associados à condição de balanço energético negativo (Ndlovu et al., 2007). Este comportamento pode ser atribuído aos menores teores de carboidratos não fibrosos, presentes nos resíduos de feijão, em comparação ao milho (Tabela 1), e nos concentrados com maiores níveis de inclusão destes resíduos (Tabela 2), além da redução no consumo de dieta (Tabela 3). Estes fatores contribuem para a 
menor disponibilidade de glicose da dieta e redução da gliconeogênese hepática, o que contribui para o balanço energético negativo. As concentrações de triglicerídeos observadas nesta pesquisa estão próximas do valor de $16,5 \mathrm{mg} \mathrm{dL}^{-1}$, registrados por Pogliani \& Birgel Junior (2007) para vacas em lactação.

O teor de creatinina não foi alterado $(p>0,05)$ pelos níveis de resíduos de feijão, antes do fornecimento do concentrado, nem duas, e seis horas após o fornecimento (Tabela 4), tendo-se observado valores médios de $0,75,1,22,0,99 \mathrm{mg} \mathrm{dL}^{-1}$, respectivamente. Porém, no tempo de quatro horas após o fornecimento do concentrado, constatou-se efeito linear positivo $(\mathrm{p}<0,05)$ dos resíduos de feijão sobre os teores de creatina, com acréscimo de $0,001 \mathrm{mg} \mathrm{dL}^{-1}$ para cada unidade percentual de resíduos de feijão adicionados ao concentrado. Os teores de creatinina se mantiveram entre os valores de referência de 0,8 e $1,4 \mathrm{mg} \mathrm{dL}^{-1}$, descritos por Kaneko et al. (2008) para bovinos sadios. A concentração sérica de ureia e creatinina permite avaliar o bom funcionamento renal, ou seja, a capacidade de excreção dos rins (Borges et al., 2008).

A concentração de ureia plasmática não foi alterada $(p>0.05)$ pelos níveis de resíduos de feijão para os diferentes tempos de amostragem (Tabela 4). Observaram-se os valores médios de $34,89,36,82$, 35,74 e $35,33 \mathrm{mg} \mathrm{dL}^{-1}$, para os níveis de 134,240 , 348 e $449 \mathrm{~g} \mathrm{~kg}^{-1}$ de resíduos de feijão na ração concentrada, respectivamente. A concentração de ureia plasmática está correlacionada à concentração de

Tabela 4. Médias, coeficiente de variação (CV) e níveis descritivos de probabilidade (valor p) para as variáveis sanguíneas: glicose, colesterol, triglicérides, creatinina, ureia e enzima gama-glutamiltransferase (GGT), coletadas em diferentes horários (antes da alimentação e 2, 4 e 6 horas após a alimentação).

\begin{tabular}{|c|c|c|c|c|c|c|c|}
\hline \multirow[t]{2}{*}{ Item } & \multicolumn{4}{|c|}{ Níveis de inclusão de resíduos de feijão $\left(\mathrm{g} \mathrm{kg}^{-1}\right)$} & \multirow{2}{*}{$\begin{array}{l}\text { CV } \\
(\%)\end{array}$} & \multicolumn{2}{|c|}{ Valor $\mathrm{p}$} \\
\hline & 134 & 240 & 348 & 449 & & Linear $^{(1)}$ & Quadrático $^{(1)}$ \\
\hline \multicolumn{8}{|c|}{ Antes da suplementação } \\
\hline Glicose (mg dL $\left.{ }^{-1}\right)$ & 47,25 & 45,13 & 45,88 & 42,88 & 10,48 & 0,1167 & 0,7998 \\
\hline Colesterol (mg dL $\left.{ }^{-1}\right)$ & 162,88 & 166,75 & 173,75 & 179,31 & 16,77 & 0,2279 & 0,9248 \\
\hline Trigricerídeos $\left(\mathrm{mg} \mathrm{dL}^{-1}\right)^{(2)}$ & 20,66 & 22,18 & 24,69 & 24,44 & 16,98 & 0,0357 & 0,5574 \\
\hline Creatinina $\left(\mathrm{mg} \mathrm{dL}^{-1}\right)$ & 0,82 & 0,72 & 0,72 & 0,74 & 38,03 & 0,6179 & 0,5545 \\
\hline Ureia $\left(m g \mathrm{dL}^{-1}\right)$ & 26,61 & 30,82 & 35,09 & 27,68 & 29,67 & 0,5847 & 0,0666 \\
\hline GGT $\left(\mathrm{U} \mathrm{L}^{-1}\right)$ & 18,14 & 15,88 & 15,98 & 16,80 & 29,70 & 0,6159 & 0,3935 \\
\hline \multicolumn{8}{|c|}{2 horas após a suplementação } \\
\hline Glicose $\left(\mathrm{mg} \mathrm{dL}^{-1}\right)^{(3)}$ & 53 & 54,25 & 49,75 & 48,13 & 8,34 & 0,0104 & 0,3292 \\
\hline Colesterol (mg dL $\left.{ }^{-1}\right)^{(4)}$ & 130,50 & 148,00 & 173,75 & 179,31 & 22,78 & 0,0065 & 0,6789 \\
\hline Trigricerídeos $\left(\mathrm{mg} \mathrm{dL}^{-1}\right)^{(5)}$ & 14,63 & 15,41 & 16,26 & 16,25 & 10,25 & 0,0344 & 0,5200 \\
\hline Creatinina $\left(\mathrm{mg} \mathrm{dL}^{-1}\right)$ & 1,15 & 1,24 & 1,18 & 1,34 & 28,41 & 0,3581 & 0,7778 \\
\hline Ureia $\left(\mathrm{mg} \mathrm{dL}^{-1}\right)$ & 34,72 & 34,44 & 32,48 & 34,13 & 21,56 & 0,7437 & 0,7271 \\
\hline GGT $\left(\mathrm{U} \mathrm{L}^{-1}\right)$ & 22,34 & 19,46 & 21,36 & 18,18 & 26,25 & 0,2280 & 0,9413 \\
\hline \multicolumn{8}{|c|}{4 horas após a suplementação } \\
\hline Glicose $\left(\mathrm{mg} \mathrm{dL}^{-1}\right)$ & 54,13 & 54,5 & 52,75 & 51,875 & 6,33 & 0,1268 & 0,5953 \\
\hline Colesterol (mg dL $\left.{ }^{-1}\right)$ & 151,81 & 153,50 & 139,44 & 147,06 & 12,73 & 0,3455 & 0,6891 \\
\hline Trigricerídeos $\left(\mathrm{mg} \mathrm{dL}^{-1}\right)^{(6)}$ & 14,24 & 15,61 & 16,18 & 13,82 & 16,45 & 0,8760 & 0,0287 \\
\hline Creatinina $\left(\mathrm{mg} \mathrm{dL}^{-1}\right)^{(7)}$ & 0,85 & 0,89 & 1,18 & 1,11 & 28,81 & 0,0310 & 0,6359 \\
\hline Ureia $\left(\mathrm{mg} \mathrm{dL}^{-1}\right)$ & 42,97 & 47,44 & 42,66 & 45,32 & 20,30 & 0,8814 & 0,7720 \\
\hline GGT $\left(\mathrm{U} \mathrm{L}^{-1}\right)^{(8)}$ & 23,41 & 19,41 & 19,86 & 17,08 & 23,75 & 0,0225 & 0,7337 \\
\hline \multicolumn{8}{|c|}{6 horas após a suplementação } \\
\hline Glicose (mg dL $\left.{ }^{-1}\right)$ & 54,25 & 52,50 & 54,38 & 52,13 & 6,70 & 0,4432 & 0,8599 \\
\hline Colesterol (mg dL $\left.{ }^{-1}\right)$ & 160,38 & 154,94 & 145,50 & 171,44 & 14,79 & 0,5465 & 0,0567 \\
\hline Trigricerídeos $\left(\mathrm{mg} \mathrm{dL}^{-1}\right)^{(9)}$ & 12,55 & 14,41 & 15,00 & 15,44 & 17,02 & 0,0262 & 0,4352 \\
\hline Creatinina $\left(\mathrm{mg} \mathrm{dL}^{-1}\right)$ & 1,07 & 0,84 & 1,10 & 0,94 & 28,66 & 0,8121 & 0,7279 \\
\hline Ureia $\left(m g \mathrm{dL}^{-1}\right)$ & 35,29 & 34,58 & 32,75 & 34,22 & 29,72 & 0,7534 & 0,7759 \\
\hline GGT $\left(\mathrm{U} \mathrm{L}^{-1}\right)$ & 25,11 & 22,23 & 20,21 & 24,81 & 28,51 & 0,7656 & 0,1125 \\
\hline
\end{tabular}

${ }^{(1)}$ Efeitos de ordem linear e quadrática relativos aos diferentes níveis de inclusão do resíduo de feijão no suplemento, respectivamente. ${ }^{(2)} \hat{Y}=19,1270+$ $0,01320 x\left(\mathrm{R}^{2}=0,69\right) ;{ }^{(3)} \hat{\mathrm{Y}}=56,5988-0,01816 \mathrm{x}\left(\mathrm{R}^{2}=0,75\right) ;{ }^{(4)} \hat{\mathrm{Y}}=109,8824+0,16399 \mathrm{x}\left(\mathrm{R}^{2}=0,68\right) ;{ }^{(5)} \hat{\mathrm{Y}}=14,0356+0,00546 \mathrm{x}\left(\mathrm{R}^{2}=0,64\right) ;{ }^{\left({ }^{6}\right)} \hat{\mathrm{Y}}=9,1093+$ $0,04885 \mathrm{x}-0,0085 \mathrm{x}^{2}\left(\mathrm{R}^{2}=0,54\right) ;{ }^{(7)} \hat{\mathrm{Y}}=0,7095+0,00100 \mathrm{x}\left(\mathrm{R}^{2}=0,61\right) ;{ }^{\left({ }^{8}\right)} \hat{\mathrm{Y}}=25,0900-0,01758 \mathrm{x}\left(\mathrm{R}^{2}=0,58\right) ;{ }^{(9)} \hat{\mathrm{Y}}=11,7721+0,00881 \mathrm{x}\left(\mathrm{R}^{2}=0,53\right)$. 
ureia no leite; tais concentrações podem ser utilizadas como indicadores dos níveis de proteína da dieta (Gandra et al., 2009). Os valores de ureia plasmática registrados nesta pesquisa estão entre $28,1 \mathrm{mg} \mathrm{dL}^{-1}$ (Ferreira et al., 2009) e 37,2 $\mathrm{mg} \mathrm{dL}^{-1}$ (Freitas Júnior et al., 2010). De acordo com Butler (2000), valores de ureia plasmática acima de $57 \mathrm{mg} \mathrm{dL}^{-1}$ são associados à diminuição da fertilidade em vacas leiteiras, por alterar os teores de ureia, $\mathrm{Mg}, \mathrm{K}, \mathrm{P}, \mathrm{Zn}$ e $\mathrm{pH}$ no útero.

A concentração da enzima gama-glutamiltransferase não apresentou efeito significativo $(p>0,05)$ quanto aos níveis de resíduos de feijão, antes do fornecimento de concentrado, nem duas e seis horas após este fornecimento, tendo-se observado valores médios de $16,70,20,33$, e 23,09 $\mathrm{U} \mathrm{L}^{-1}$, respectivamente. Todavia, verificou-se comportamento linear $(p<0,05)$ da gama-glutamiltransferase, em consequência dos níveis de resíduos de feijão, para o tempo de quatro horas após o fornecimento de concentrado, com estimativa de redução de $0,017 \mathrm{U} \mathrm{L}^{-1}$, para cada unidade percentual de resíduos de feijão adicionados ao concentrado. $\mathrm{O}$ aumento da gama-glutamiltransferase no plasma sanguíneo de grandes animais é indicativo de lesão hepática e obstrução biliar, conforme Butler (2000), que afirma que que os valores de referência para esta enzima estão entre 15 e $39 \mathrm{U} \mathrm{L}^{-1}$, os quais abrangem os valores encontrados no presente trabalho.

\section{Conclusões}

Ainclusão de resíduos de feijão na ração concentrada para vacas leiteiras em pastejo com produção média diária de $13 \mathrm{~kg}$ reduz a produção de leite; no entanto, a utilização deste resíduo pouco influencia a composição do leite e os parâmetros sanguíneos dos animais.

\section{Agradecimentos}

Ao Conselho Nacional de Desenvolvimento Científico e Tecnológico $(\mathrm{CNPq})$ e à Fundação de Amparo à Pesquisa do Estado de Mato Grosso (Fapemat), pelo apoio financeiro; à Coordenação de Aperfeiçoamento de Pessoal de Nível Superior (Capes), por concessão de bolsa; à Empresa de Pesquisa Agropecuária de Minas Gerais (Epamig), por ceder a fazenda experimental e animais para a realização deste trabalho; à Universidade Federal de São João del-Rei (UFSJ), pela utilização do Laboratório de Análises de Alimentos.

\section{Referências}

ACOMPANHAMENTO DA SAFRA BRASILEIRA [DE] GRÃOS. Brasília: Conab, v.1, n.3, 2013. Safra 2013/14, terceiro levantamento.

BARLETTA, R.V.; RENNÓ F.P.; GANDRA, J.R.; FREITAS JÚNIOR, J.É. de; VERDURICO, L.C.; MINGOTI, R.D.; VILELA, F.G. Desempenho e parâmetros sanguíneos de vacas leiteiras alimentadas com grão de soja. Archivos de Zootecnia, v.61, p.483-492, 2012. DOI: 10.4321/S0004-05922012000400001.

BONETT, L.P.; BAUMGARTNER, M. do S.T.; KLEIN, A.C.; SILVA, L.I. da. Compostos nutricionais e fatores antinutricionais do feijão comum (Phaseolus Vulgaris L.). Arquivos de Ciências da Saúde da Unipar, v.11, p.235-246, 2007.

BORGES, K.E.; POLIZER, K.A.; SILVÉRIO, M.R.; GIMENES, T.F.; BERMEJO, V.J. Exames de função renal utilizados na medicina veterinária. Revista Científica Eletrônica de Medicina Veterinária, v.6, 2008.

BRASIL. Ministério da Agricultura, Pecuária e Abastecimento. Instrução Normativa n. ${ }^{\circ}$ 62, de 29 de dezembro de 2011. [Altera o caput, exclui o parágrafo único e insere os ${ }^{-1} 1^{\circ}$ e $3^{\circ}$, todos do art. $1^{\circ}$, da Instrução Normativa MAPA $n^{\circ} 51$, de 18 de setembro de 2002]. Diário Oficial [da] República Federativa do Brasil, Brasília, DF, 30 dez. 2011. Seção 1, p.6-11.

BUENO, V.F.F.; MESQUITA, A.J. de; NICOLAU, E.S.; OLIVEIRA, A.N. de; OLIVEIRA, J.P. de; NEVES, R.B.S.; MANSUR, J.R.G.; THOMAZ, L. W. Contagem celular somática: relação com a composição centesimal do leite e período do ano no Estado de Goiás. Ciência Rural, v.35, p.848-854, 2005. DOI: 10.1590/S0103-84782005000400016.

BUTLER, W.R. Nutritional interactions with reproductive performance in dairy cattle. Animal Reproduction Science, v.60-61, p.449-457, 2000. DOI: 10.1016/S0378-4320(00)00076-2.

CALIXTO JUNIOR, M.; JOBIM, C.C.; SANTOS, G.T. dos; BUMBIERIS JÚNIOR, V.H. Constituintes sanguíneos de vacas da raça Holandesa alimentadas com silagens de milho ou de capim-elefante. Semina: Ciências Agrárias, v.31, p.429-437, 2010. DOI: $10.5433 / 1679-0359.2010 v 31 \mathrm{n} 2 \mathrm{p} 429$.

DETMANN, E.; SOUZA, M.A.; VALADARES FILHO, S.C.; QUEIROZ, A.C.; BERCHIELLI, T.T.; SALIBA, E.O.S.; CABRAL, L.S.; PINA, D.S.; LADEIRA, M.M.; AZEVEDO, J.A.G. Métodos para análise de alimentos: INCT: Ciência animal. Visconde do Rio Branco: Suprema, 2012. 214p.

DUARTE, L.M.D'A.; STUMPF JUNIOR, W.; FISCHER, V.; SALLA, L.E. Efeito de diferentes fontes de gordura na dieta de vacas Jersey sobre o consumo, a produção e a composição do leite. Revista Brasileira de Zootecnia, v.34, p.2020-2028, 2005. DOI: 10.1590/S1516-35982005000600027.

EUCLIDES, V.P.B.; LOPES, F. da C.; NASCIMENTO JUNIOR, D. do; SILVA, S.C. da; DIFANTE, G. dos S.; BARBOSA, R.A. Steer performance on Panicum maximum (cv. Mombaça) pastures under two grazing intensities. Animal Production Science, 2015. DOI: $10.1071 /$ an14721. 
FERREIRA, A. de M.; TORRES, C.A.A. Perda de peso corporal e cessação da atividade ovariana luteínica cíclica em vacas mestiças leiteiras. Pesquisa Agropecuária Brasileira, v.28, p.411-418, 1993.

FERREIRA, A.C.H.; NEIVA, J.N.M.; RODRIGUEZ, N.M.; SANTANA, G.Z.M.; BORGES, I.; LÔBO, R.N.B. Desempenho produtivo de ovinos alimentados com silagens de capim-elefante contendo subprodutos do processamento de frutas. Revista Ciência Agronômica, v.40, p.315-322, 2009.

FREITAS JÚNIOR, J.E. de; RENNÓ, F.P.; SILVA, L.F.P. e; GANDRA, J. R.; MATURANA FILHO, M.; FODITSCH, C.; VENTURELLI, B.C. Parâmetros sanguíneos de vacas leiteiras suplementadas com diferentes fontes de gordura. Ciência Rural, v.40, p.950-956, 2010. DOI: 10.1590/S0103-84782010005000039.

GANDRA, J.R.; RENNÓ, F.P.; SILVA, L.F.P.; FREITAS JÚNIOR, J.É.; MATURANA FILHO, M.; GANDRA, É.R. de S.; D'ANGELO, L.S.; ARAÚJO, A.P.C. Parâmetros sanguíneos de vacas leiteiras submetidas à diferentes níveis de monensina sódica nas rações. Revista Brasileira de Saúde e Produção Animal, v.10, p.115-128, 2009.

GOES, R.H. de T. e B. de; KLEIN, K.W.; MARTINHAGO, L.H.; OLIVEIRA, E.R. de; BRABES, K.C. da S.; GRESSLER, M.G. de M.; YOSHIRAHA, M.M.; OLIVEIRA, R.T. de; SANTOS, E.M.L. de. Common beans (Phaseolus vulgaris L.) in the rations for cattle in feedlot. Agricultural Sciences, v.4, p.774-780, 2013. DOI: 10.4236/as.2013.412106.

KANEKO, J.J.; HARVEY, J.W.; BRUSS, M.L. Clinical biochemistry of domestic animals. $6^{\text {th }}$ ed. San Diego: Academic Press, 2008. 916p. DOI: 10.1016/B978-0-12-370491-7.00035-0.

MACIEL, R.P.; NEIVA, J.N.M.; ARAÚJO, V.L. de; CUNHA, O.F.R.; PAIVA, J.; RESTLE, J.; MENDES, C.Q.; LÔBO, R.N.B. Consumo, digestibilidade e desempenho de novilhas leiteiras alimentadas com dietas contendo torta de dendê. Revista Brasileira de Zootecnia, v.41, p.698-706, 2012. DOI: 10.1590/ S1516-35982012000300033.

MAGALHÃES, A.L.R.; ZORZI, K.; QUEIROZ, A.C. de; MELLO, R.; DETMANN, E.; PEREIRA, J.C. Resíduo proveniente do beneficiamento do feijão (Phaseolus vulgaris L.) em rações para vacas em lactação: consumo, digestibilidade, produção e composição do leite e eficiência de alimentação. Revista Brasileira de Zootecnia, v.37, p.529-537, 2008. DOI: 10.1590/ S1516-35982008000300019.

MENDES NETO, J.; CAMPOS, J.M. de S.; VALADARES FILHO, S. de C.; LANA, R. de P.; QUEIROZ, A.C. de; EUCLYDES, R.F. Consumo, digestibilidade, desempenho, desenvolvimento ponderal e economicidade de dietas com polpa cítrica em substituição ao feno de capim-tifton 85 para novilhas leiteiras. Revista Brasileira de Zootecnia, v.36, p.626-634, 2007. DOI: 10.1590/ S1516-35982007000300016.
NATIONAL RESEARCH COUNCIL. Nutrient requirements of dairy cattle. $1^{\text {th }}$ ed. Washington: National Academic Press, 2001. 381p. DOI: $10.17226 / 9825$.

NDLOVU, T.; CHIMONYO, M.; OKOH, A.I.; DZAMA, K.; RAATS, J.G. Assessing the nutritional status of beef cattle: current practices and future prospects. African Journal of Biotechnology, v.6, p.2727-2734, 2007. DOI: 10.5897/ AJB2007.000-2436.

OLIVEIRA, A.G. de; OLIVEIRA, V.S. de; SANTOS, G.R. de A.; SANTOS, A.D.F.; SANTOS SOBRINHO, D.C. dos; OLIVEIRA, F.L. de; SANTANA, J.A.; GOVEIA, J.S.S. Desempenho de vacas leiteiras sob pastejo suplementadas com níveis de concentrado e proteína bruta. Semina: Ciências Agrárias, v.35, p.3287-3304, 2014. DOI: $10.5433 / 1679-0359.2014 v 35 n 6 p 3287$.

PAIVA, V.R.; LANA, R.P.; OLIVEIRA, A.S.; LEÃO, M.I.; TEIXEIRA, R.M.A. Teores proteicos em dietas para vacas Holandesas leiteiras em confinamento. Arquivo Brasileiro de Medicina Veterinária e Zootecnia, v.65, p.1183-1191, 2013. DOI: $10.1590 / \mathrm{S} 0102-09352013000400034$.

PEDREIRA, B.C. e; PEDREIRA, C.G.S. Fotossíntese foliar do capim-xaraés [Brachiaria brizantha (A. Rich.) Stapf. cv. Xaraés] e modelagem da assimilação potencial de dosséis sob estratégias de pastejo rotativo. Revista Brasileira de Zootecnia, v.36, p.773-779, 2007. DOI: $10.1590 / \mathrm{S} 1516-35982007000400004$.

PIMENTEL, J.J. de O.; LANA, R. de P.; TEIXEIRA, R.M.A.; ABREU, D.C. de; GHEDINI, C.P. Produção de leite em função de níveis de suplementação com concentrados para vacas leiteiras pastejando capim-elefante. Revista Brasileira de Higiene e Sanidade Animal, v.7, p.61-78, 2013. DOI: 10.5935/1981-2965.20130005.

POGLIANI, F.C.; BIRGEL JUNIOR, E. Valores de referência do lipidograma de bovinos da raça holandesa, criados no Estado de São Paulo. Brazilian Journal of Veterinary Research and Animal Science, v.44, p.373-383, 2007. DOI: 10.1590/ S1413-95962007000500009.

ROSA, D.C.; TRENTIN, J.M.; PESSOA, G.A.; SILVA, C.A.M.; RUBIN, M.I.B. Qualidade do leite em amostras individuais e de tanque de vacas leiteiras. Arquivos do Instituto Biológico, v.79, p.485-493, 2012. DOI: 10.1590/S1808-16572012000400004.

RYSANEK, D.; BABAK, V. Bulk tank milk somatic cell count as an indicator of the hygiene status of primary milk production. Journal of Dairy Research, v.72, p.400-405, 2005. DOI: 10.1017/ S002202990500097X.

SKLAN, D.; ASHKENAZI, R.; BRAUN, A.; DEVORIN, A.; TABORI, K. Fatty acids, calcium soaps of fatty acids, and cottonseeds fed to high yielding cows. Journal of Dairy Science, v.75, p.2463-2472, 1992. DOI: 10.3168/jds. S0022-0302(92)78008-4.

Recebido em 30 de abril de 2015 e aprovado em 18 de novembro de 2015 